\title{
Goldenhar Sendromu: Olgu Sunumu
}

\author{
"Goldenhar Syndrome: Case Report" \\ Abdurrahman Avar Özdemir ${ }^{1}$, Yakup Çağ ${ }^{2}$
}

${ }^{1}$ Çocuk Sağlığı ve Hastalıkları, İstanbul Medicine Hospital, ìstanbul 2 Çocuk Sağlığı ve Hastalikları, U Istanbul Anadolu Güney Kamu Hastaneleri Birliği Genel Sekreterliği / Sultanbeyli Devlet Hastanesi, istanbul

Correspondence / Yazışma Adresi:

\section{Abdurrahman Avar Özdemir}

İstanbul Medicine Hospital, Yenidoğan Yoğun Bakım Ünitesi Barbaros Mah. Hoca

Ahmet Yesevi Cad. No:149 Güneşli/istanbul

Geliş Tarihi / Received : 03.05.2017

P: 05323674581

E-mail: avarozdemir@gmail.com

Kabul Tarihi / Accepted : 25.08.2017

\section{Özet}

Goldenhar Sendromu fasiyal asimetri, kulak, göz ve vertebra anomalilerini içeren konjenital bir hastalıktır. Sendromun sıklığı 1:3500 ile 1:7000 arasında değismektedir. Vakaların çoğu sporadiktir ve ailesel geçiş nadiren görülür. Hastalı̆ın etyolojisi hala bilinmemekte, ancak embriyonal dönemde ortaya çıkan gelişim bozukluğunun bu hastalıkta görülen anomalilere yol açıı̆ı düşünülmektedir. Bu makalede Goldenhar Sendromu tanısı alan bir yenidoğan olgusu eşlik eden anomalilere dikkat çekmek için sunulmuştur ( Sakarya Tip Dergisi 2017, 7(3):149-153 ).

Anahtar Kelimeler: Hemifasiyal mikrozomi, Kardiyak anomali, Renal anomali

\section{Abstract}

Goldenhar's syndrome is a rare congenital syndrome, characterized with facial asymmetry, ear, eye, and vertebral anomalies. The incidence of Goldenhar syndrome has been reported to be between 1:3500 to 1:7000. Most of the cases were sporadic and in some cases positive family histories have been present. There is not enough information to identify its etiologic factors. It is suggested a disturbance of embryonal stage as the cause of disease. Herein, we report a newborn with Goldenhar Syndrome because of this rare condition and accompanying abnormalities. ( Sakarya Med J 2017, 7(3):149-153 )

Keywords Hemifacial Microsomia, Cardiac abnormality, Renal abnormality 


\section{Giriş}

Goldenhar Sendromu (GS) fasiyal asimetri, kulak, göz ve vertebra anomalilerini içeren nadir görülen konjenital bir hastalıktır (OMIM \%164210). M. Goldenhar tarafindan göz ve kulak bulgularıla tanımlanan bu sendrom hemifasiyal mikrozomi ya da okülo-aurikulo-vertebral displazi adı ile de anılmaktadır. ${ }^{1-3}$ Sendromun sıklığı 1/3500-7000 ve erkek/kız oranı 3/2'dir. ${ }^{4}$ Vakaların çoğu sporadik olmakla beraber otosomal dominant ve otosomal resesif geçişe uyan vakalar da bildirilmiştir. ${ }^{5,6}$ Embriyonal dönemde ortaya çıkan gelişim bozukluğunun bu hastalıkta görülen anomalilere yol açtığı düşünülmektedir. ${ }^{1,2,4,5}$ Bu sendromda sıklıkla görülen mikrotia, anotia, preaurikular skin tag, hemifasiyal mikrozomi, epibulbar dermoidler, vertebra ve diğer iskelet anomalileri gibi klinik bulgulara kardiyak ve renal anomaliler de eşlik edebilmektedir. ${ }^{1-7}$

Bu makalede Goldenhar Sendromu tanısı konan yenidoğan olgusu nadir görülmesi ve eşlik eden diğer anomalileri nedeni ile sunuldu.

\section{Olgu Sunumu}

22 yaşındaki annenin ilk gebeliğinden, 39 haftalık olarak doğan erkek bebeğin yapılan ilk muayenesinde doğum tartısı 2500 gr (<3.p) boyu $48 \mathrm{~cm}$ (10.p) ve baş çevresi $32 \mathrm{~cm}$ (3.p) bulundu. Sağ kulak kepçesi olmayan bebeğin (anotia), dış kulak yolu atrezik ve deri katlantısı (skin tag) bulunmaktaydı (Resim 1).

Resim1. Atrezik dış kulak yolu.

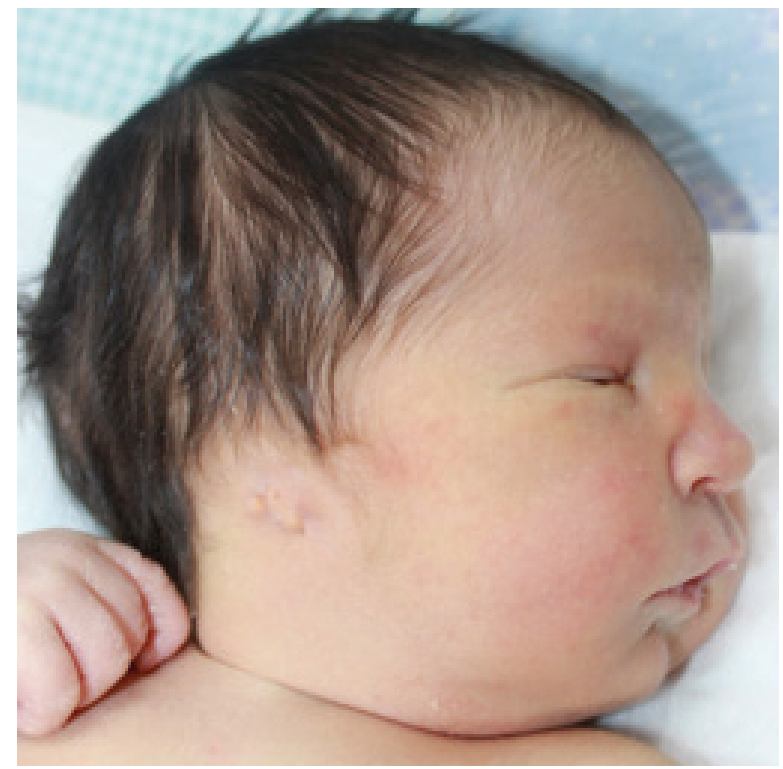

Hasta ağlarken ağız ve yüzün sola kaydığı, sağda nazolabial sulkusların silik olduğu, sağ gözün tam kapanmadığı (fasiyal paralizi), sağ gözün sol göze kıyasla küçük olduğu (mikroftalmi) saptandı (Resim 2).

Resim 2. Sağ gözde mikroftalmi.

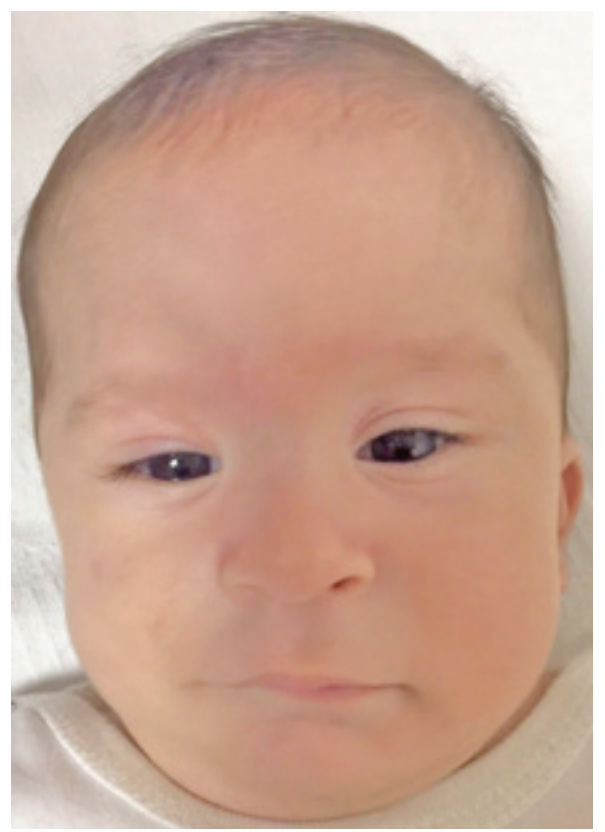

Solunumu rahat ve doğal olan bebeğin kardiyovasküler muayenesinde 1-2/6 üfürüm tespit edildi. Üfürüm nedeniyle yapılan ekokardiyografik incelemede müsküler tip ventriküler septal defekt (VSD) ve sekundum tip atriyal septal defekt (ASD) saptandı. Ek anomali varlığını araştırmak için bakılan iskelet grafileri ve kranial ultrasonografisi normal bulundu, batın ultrasonografisinde ise sağ böbrek görülemedi (agenezi). Göz muayenesinde sağda mikroftalmi dışında özellik saptanamayan hastanın işitmesini değerlendirmek amacıyla yapılan beyin sapı işitsel uyarılmış potansiyel (BERA) testine sağ tarafta cevap alınamadı. Olgunun kranial bilgisayarlı tomografi (BT) incelemesinde ek anomali saptanmadı. Genetik incelemesinde karyotipi $46 \mathrm{XY}$ olarak saptanan hastada mevcut bulgular ile Goldenhar Sendromu düşünülerek poliklinikten takip edilmek üzere taburcu edildi.

\section{Tartışma}

Ilk kez 1952 yılında Maurice Goldenhar tarafından tanımlanan bu sendrom, 1963 yilında Gorlin ve arkadaşları tarafından vertebra 
bulgularının tanıma eklenmesiyle okülo-aurikulo-vertebral (OAV) spektrum ya da displazi adıyla anılmaya başlanmıştı. ${ }^{1-3}$

GS'nun etyolojisi hala bilinmemekte olup embriyonal dönemde, 1. ve 2. brankial arklarda, vasküler hasar ya da mesodermal migrasyondaki aksama sonucunda ortaya çıkan gelişim bozukluğunun bu hastalıkta görülen kraniyofasiyal anomalilere yol açtı̆̆ düşünülmektedir. ${ }^{1,2,4,5}$ Gebelikte alınan talidomid, retinoik asit, tamoxifen gibi ilaçlar, kokain ve fazla alkol tüketimi, yardımcı üreme tekniklerinin kullanımının yanı sıra maternal diyabet, rubella ve influenza da suçlanan faktörler arasındadır. ${ }^{2,6-8}$ Bu olguda ailede benzer bulguları olan birey yoktu ve olgunun kromozom analizi normaldi. Bu nedenle olgunun sporadik olduğu düşünüldü. Etyolojik faktörler arasında olabileceği düşünülen gebelikte ilaç alımı ve geçirilmiş hastalık öyküsü bizim olgumuzda mevcut değildi.

Goldenhar sendromunda tanı klinik ve radyolojik bulgulara dayanarak konulmaktadır. Vakaların \%85'inde bulgular unilateral olup, bilateral tutulum \%10-33'ünde görülmektedir. ${ }^{2,6}$ En sık olarak kulak, göz, kranio-fasiyal ve vertebral anomaliler görülmekle birlikte kulak anomalilerinin varlığı birçok uzman tarafından tanı için gerekli görülmektedir. ${ }^{6}$ Barisiç ve ark.nın okülo-aurikulo-vertebral spektrum tanılı 355 vaka üzerinde yaptığı bir çalışmada en sık kulak anomalileri görülürken (\%88) bunu hemifasiyal mikrozomi (\%49), vertebra (\%24) ve göz anomalileri (\%24) izlemekte olup Engiz ve ark.'nın 31 vakalık sunumunda da bulgular benzer sıklıktadır. ${ }^{7,9} \mathrm{Bi}$ zim olgumuzda da literatür ile uyumlu olarak kulak ve göz bulguları unilateral idi.

Sık görülen kulak anomalileri içinde anotia, mikrotia, preaurikular skin tag, dış kulak yolu atrezisi/stenozunun yanı sıra iç kulak yolu anomalileri ve işitme kaybı görülebilmektedir. ${ }^{3,7,10}$ Bizim olgumuzda bu bulgularla uyumlu olarak anotia, skin tag, dış kulak yolu atrezisi ve sağ tarafta iletim tipi işitme kaybı bulunmakta idi.

Diğer sık görülen anomaliler, kraniofasiyal anomaliler (hemifasiyal mikrozomi, maksiller ve zigomatik hipoplazi, mandibular asimetri ve hipoplazi, fasiyal paralizi, makrostomi, yarık damak/dudak), göz anomalileri (mikroftalmi, epibulbar dermoidler, alt ve üst göz kapağı kolobomu, optik sinir kolobomu, oküler direnaj anomalile- ri) ve vertebral anomalileri (hemivertebra, sinostozis, vertebral ve servikal füzyon) içermektedir. ${ }^{1,5-9,11}$ Benzer şekilde olgumuzda hemifasiyal mikrozomi, fasiyal paralizi, gözde mikroftalmi anomalileri mevcut olup vertebral anomali saptanmadı.

Bu sendromda diğer sistemleri etkileyen anomaliler de görülmektedir. Bunlar içinde en sık kardiyovasküler anomaliler (VSD, ASD, ventriküler hipertrofi ve Fallot Tetralojisi) görülmekte olup bunu genitoüriner anomaliler (ektopik böbrek, renal agenezi, üreteropelvik darlık, üreteral duplikasyon) izlemektedir. Bunlar dışında solunum sistemi (larengeal hipoplazi, akciğer hipoplazisi), gastrointestinal sistem (trakeaözefageal fistül, imperfore anüs), santral sinir sistemi (korpus kollosum agenesisi, septum pellusidum hipoplazisi, intrakranial dermoid kist) anomalileri de görülmektedir. ${ }^{1-3,6,7}$ Bizim olgumuzda bu verilerle uyumlu olarak VSD, ASD ve sağ renal agenezi mevcuttu ancak santral sinir sistemi anomalisi saptanmadı.

GS'da \%10-25 sıkıkta mental retardasyon görülebilmektedir. Bu nedenle hastaların uzun süreli nörolojik takibi önemlidir. Bizim olgumuzun nörolojik muayenesi normal olmakla beraber mental sorunların yenidoğan dönemi sonrasında ortaya çıkma olasılığı nedeni ile takibe alındı.

Olgumuz sendromun temel özelliklerinin çoğunu taşıdığı için tanı kolaylıkla kondu. Bununla birlikte sendromun klasik özelliklerinin bulunmadığı vakalarda tanı koymak zor olabilir. Benzer bulgular gösteren Brakio-oto-renal sendrom, Wildervanck sendromu, DiGeorge sekansı, Treacher-Collins sendromu ayırıcı tanıda düşünülmesi gereken hastalıklardır. ${ }^{3,5,8}$

Komplike olmayan vakalarda temel olarak tedavi kozmetiktir. Hasta rekonstrüksiyon cerrahisi ile birlikte değerlendirilmeli; yüz, kemik doku ve göz bulguları için uygun operasyon ve zaman aile ile birlikte kararlaştııımalıdır. Komplike olan vakalar ise doğum sonrası başlayabilen solunum sıkıntısı, beslenme sorunları, işitme sorunları, kardiyak, üriner sorunlar için yakından takip edilmeli ve multidisipliner bir yaklaşım gösterilmelidir. Hastanın karşı karşıya bulunduğu sorunlar nedeni ile psikososyal destek ihmal edilmemelidir. Hastalığın prognozu komplike olmayan vakalarda oldukça iyidir ancak komplike vakalarda prognoz sistemik tutulumun şiddetine 
göre değişmektedir. ${ }^{1,2,12}$

Sonuç olarak Goldenhar Sendromu tanısı konan hastalar klasik bulgulara eşlik edebilen diğer sistem anomalileri nedeni ile multidisipliner bir yaklaşım ile değerlendirilmelidir. Hastalar uzun dönemde karşılaşabilecekleri işitsel, psikososyal ve mental sorunlar için takip edilmeli, doğacak diğer çocuklarda hastalı̆ın tekrarlama riski nedeni ile ailelere genetik danışma verilmelidir.

\section{Çıkar Çatışması:}

Makale ile ilgili üçüncü kişi ve kurumlardan destek alınmamıştır ve çıkar çatışması bulunmamaktadır. Hastanın anne ve babasından yazılı onam alınmıştır. 
1. Jones KL. Oculo-auriculo-vertebral spectrum. In: Smith's Recognizable patterns of Human Malformation. 5th ed. Philadelphia: W.B. Saunders; 1997. p. 642-645.

2. Ashokan CS, Sreenivasan A, Saraswathy GK. Goldenhar syndrome: Rewiev with the case series. J Clin Diagn Res 2014;8:17-19.

3. Kokavec R. Goldenhar syndrome with various clinical manifestations. Cleft Palate Craniofacial J 2006;43:628-634.

4. De Golovine S, Wu S, Hunter JV, Shearer WT. Goldenhar syndrome: a cause of secondary Immunodeficiency. Allergy Asthma Clin Immunol 2012;8:10.

5. Mıhçı E, Taçoy Ş, Kardelen F, Duranoğlu Y, Fişenk F. Okulo-aurikulo-vertebral spektrumlu yedi vakanın değerlendirilmesi. Cocuk Sagligi Hast Derg 2005; $48: 39-45$.

6. SharmaJK, Pippal SK, Raghuvanshi SK, Shitij A. Goldenhar-Gorlin's syndrome: a case report. Indian J Otolaryngol Head Neck Surg 2006;58:97-101.

7. Barisic I, Odak L, Loane M, Garne E, Wellesley D, Calzolari E, et al. Prevalence, prenatal diagnosis and clinical features of oculo-auriculovertebral spectrum: a registry-based study in Europe. Eur J Hum Genet 2014;22:1026-1033.

8. Elkıran Ö, Yılmaz E, Çıtak Kurt N, Akarsu S, Kurt A, Aygün D. Yenidoğan Döneminde Tanımlanan Goldenhar Sendromu: Olgu sunumu. Abant Med J 2012;1:79-82.

9. Engiz O, Balci S, Unsal M, Ozer S, Oguz KK, Aktas D. 31 cases with oculoauriculovertebral dysplasia (Goldenhar syndrome): clinical, neuroradiologic, audiologic and cytogenetic findings. Genet Couns 2007;18:277-288.

10. Sleifer P, De Souza Gorsky N, Goetze, Rosa RF, Gazzola Zen PR. Audiological findings in patients with Oculo-Auriculo-Vertebral Spectrum. Int Arch Otorhinolaryngol 2015;19:5-9.

11. Bruè C, Mariotti C, Celani S, Rossiello I, Giovannini A. A Case of Goldenhar Syndrome Associated with a New Retinal Presentation: Exudative Vitelliform Maculopathy. Case Rep Ophthalmol Med Available at: http://dx.doi. org/10.1155/2015/626027

12. Patil NA, Patil AB. Goldenhar syndrome: Case report. IJSS Journal of Surgery 2015;1:18-20. 